\title{
Multi-Area Unit Commitment Using Hybrid Particle Swarm Optimization Technique with Import and Export Constraints
}

\author{
S. R. P. CHITRA SELVI ${ }^{1}$, R. P. KUMUDINI DEVI ${ }^{2}$, C. CHRISTOBER ASIR RAJAN ${ }^{3}$ \\ ${ }^{1}$ Department of Electrical Engineering, Anna University, Chennai, India \\ ${ }^{2}$ Department of Electrical Engineering, Anna University, Chennai, India \\ ${ }^{3}$ Department of Electrical Engineering, Pondicherry Engg.College, Pondicherry, India \\ E-mail:prakasini2004@yahoo.co.in,kumudinidevi@annauniv.edu,asir_70@hotmail.com \\ Received January 10, 2009; revised February 21, 2009; accepted February 23, 2009
}

\begin{abstract}
This paper presents a novel approach to solve the Multi-Area unit commitment problem using particle swarm optimization technique. The objective of the multi-area unit commitment problem is to determine the optimal or a near optimal commitment strategy for generating the units. And it is located in multiple areas that are interconnected via tie lines and joint operation of generation resources can result in significant operational cost savings. The dynamic programming method is applied to solve Multi-Area Unit Commitment problem and particle swarm optimization technique is embedded for computing the generation assigned to each area and the power allocated to all committed unit. Particle Swarm Optimization technique is developed to derive its Pareto-optimal solutions. The tie-line transfer limits are considered as a set of constraints during the optimization process to ensure the system security and reliability. Case study of four areas each containing 26 units connected via tie lines has been taken for analysis. Numerical results are shown comparing the cost solutions and computation time obtained by using the Particle Swarm Optimization method is efficient than the conventional Dynamic Programming and Evolutionary Programming Method.
\end{abstract}

Keywords: Multi-Area Unit Commitment, Evolutionary Programming, Dynamic Programming Method, Particle Swarm Optimization Method

\section{Introduction}

In an interconnected system, the objective is to achieve the most economical generation that could satisfy the local demand without violating tie-line capacity constraints. Due to inter-area transmission constraints, multiarea unit commitment problems (MAUC) are very complicated when compared with single-area unit commitment problems. Research explores that the application of these existing single-area unit commitment to multi-area unit commitment problem is required [1-4].

Furthermore, unit commitment is treated, as separately from the economic dispatch, the linear fuel cost curve may be an expensive operation schedule or a violation of spinning reserve requirements. In multi-area systems, local generations are not equal to local load demands. Areas with lower fuel cost units may generate more power than their demand and export the excessive energy to the deficient areas; likewise, areas with higher fuel cost units will generate less power than their demand and import the additional energy from other areas with surplus capacity. So, the unit commitment of an area should comply with the local generation as well as the local load demand. References [5-11] provide comprehensive study on multi-area scheduling by relating unit commitment and economic dispatch with tie-line constraints. The following paragraph discusses some of the method, which is adopted in the multi-area unit commitment problem and their implications.

There are some drawbacks in implementing the simple priority list method for unit commitment. Although the technique was fast, the results are far from optimal, especially when there are massive on/off transitions. Another difficulty is in which did not deal with topological 
connections in a multi-area system as it considered export/import limitations, which would cause infeasible solutions in many applications. Another approach [6] overcame the previous difficulties. It considered the topological constraints and enhanced unit commitment with economic dispatch. The $\lambda$ iteration method takes excessive time in finding the optimal solution in large-scale power systems and the speed of the algorithm required some improvement. In the iterative procedure between unit commitment and economic dispatch, there is a need to adjust the unit commitment according to the required area generation. If we use Dynamic Programming Sequential Combination (DP-SC) for unit commitment in a power pool, the search for an optimal solution is very time consuming. If we adopt the priority list method, there may be a solution gap between the resultant schedule and the actual economic operation schedule. If we repeat the process, we may reduce the operation cost, but it will demand a longer execution time. The DP-SC method is used for unit-commitment problem in an interconnected area and particle swarm optimization technique is embedded for assigning generation to each area and modifying the economic dispatch schedule.

In this paper, we propose a more efficient approach to the multi-area generation dispatch problem. The proposed technique is used to improve the speed and reliability of the optimal search process. Instead of using $\lambda$ iteration method in assigning power generation to each area, we used particle swarm optimization to find the optimal allocation of power generation in each area and entire system. Using particle swarm optimization techniques in each area and entire system, we can save time in performing the economic dispatch and operating cost.

The meta-heuristic methods [12-19] are iterative techniques that can search not only local optimal solutions but also a global optimal solution depending on the problem domain and time limit. In the meta-heuristic methods, the techniques frequently applied to the UC problem are genetic algorithm (GA), tabu search (TS), evolutionary programming (EP), simulated annealing (SA), particle swarm optimization (PSO), etc. They are general-purpose search techniques based on the principles inspired from the genetic and evolution mechanisms observed in natural systems and populations of living beings. These methods have the advantage of searching the solution space more thoroughly. The main difficulty is their sensitivity to the choice of parameters.

In this paper, section one introduces that the mathematical model of the multi-area unit commitment problem. In the problem formulation, DP method is used for committing the unit in each area and $\lambda$ iteration method is used for importing and exporting power to other area and minimizes the operating cost. Furthermore, tie-line transfer capacities and area spinning reserve requirements are also incorporated in order to ensure system security and reliability. The Reserve-sharing scheme is used to enable the area without enough capacity to meet its reserve demand. The objective of MAUC, constraints and conditions of optimal solution are also discussed in this section. Section 3 and 4 explains the EP and PSO algorithm adopted for importing and exporting power to other area. Section 5 gives the results of a case study each one based on a four-area system. A four-area IEEE test power system [6] is then used as an application example to verify the effectiveness of the proposed method through numerical simulations. A comparative study is also made here to illustrate the different solutions obtained based on conventional, EP and PSO methods. Conclusions are presented in the last section.

\section{Problem Formulation}

The cost curve of each thermal unit is in quadratic form

$$
F\left(P g_{i}^{k}\right)=a_{i}^{k}\left(P g_{i}^{k}\right)^{2}+b_{i}^{k}\left(P g_{i}^{k}\right)+c_{i}^{k}: \$ / \mathrm{hr} \mathrm{k}=1 \mathrm{~N}_{\mathrm{A}}
$$

The incremental production cost is therefore

$$
\lambda=2 a_{i}^{k} P g_{i}^{k}+b_{i}^{k}
$$

or

$$
P g_{i}^{k}=\lambda-b_{i}^{k} / 2 a_{i}^{k}
$$

The start up cost of thermal unit is an exponential function of the time that the unit has been off

$$
S\left(X_{i, j}^{o f f}\right)=A_{i}+B_{i}\left(1-e^{X_{i, j}^{o f f}}\right)
$$

\subsection{Multi-Area Unit Commitment}

The objective function for the multi-area unit commitment is to minimize the entire power pool generation cost as follows:

$$
\min _{I, P} \sum_{k=1}^{N} \sum_{j=1}^{t} \sum_{i=1}^{N_{k}}\left[I_{i, j}^{k} F_{j}^{k}\left(P g_{i, j}^{k}\right)+I_{i, j}\left(1-I_{i, j-1}\right) S_{i}\left(X_{i, j-1}^{\text {off }}\right)\right.
$$

and the following constraints are to be met for optimization

1) System power balance constraints

$$
\sum_{k} P g_{j}^{k}=\sum_{k} D_{j}^{k}+W_{j} ; j=1 \ldots \ldots . . t
$$

where $\sum_{k} P g_{j}^{k}=\sum_{k} P g_{i, j}^{k}$

2) Spinning reserve constraints in each area

$$
\sum_{i} \overline{P g_{i}^{k}} \geq D_{j}^{k}+R_{j}^{k}+E_{j}^{k}-L_{j}^{k} ; \mathrm{j}=1 \ldots \mathrm{t}
$$

3) Generation limits of each unit

$$
\underline{P g}_{j}^{k} \leq P g_{i, j}^{k} \leq \overline{P g_{j}^{k}} ; \mathrm{i}=1 \ldots \mathrm{N}_{\mathrm{k}} ; \mathrm{j}=1 \ldots \mathrm{t} ; \mathrm{k}=1 \ldots \mathrm{N}_{\mathrm{A}}
$$


4) Minimum Up and Down time constraints

$$
\begin{aligned}
& \left(X_{i, j-1}^{\text {off }}-T_{i}^{\text {on }}\right) *\left(I_{i, j-1}-I_{i, j}\right) \geq 0 \\
& \left(X_{i, j-1}^{\text {off }}-T_{i}^{\text {off }}\right) *\left(I_{i, j-1}-I_{i, j}\right) \geq 0
\end{aligned}
$$

To decompose the problem in Equation (5), it is rewritten as

$$
\min _{P} \sum_{j=1}^{t}\left[F\left(P g_{i, j}\right)\right]
$$

where

$$
F\left(P g_{i, j}\right)=\sum_{k=1}^{N_{k}} F^{k}\left(P g_{i, j}^{k}\right)
$$

subject to the constraints of Equation (6) and (8) and following constraints.

5) Export/Import constraints

$$
\begin{gathered}
\sum_{i} P g_{i . j}^{k} \leq D_{j}^{k}+E_{j \max }^{k} \\
\sum_{i} P g_{i, j}^{k} \geq \sum_{k} D_{j}^{k}-L_{j \max }^{k} \\
\sum_{i} E_{j}^{k}-\sum_{k} L_{j}^{k}+W_{j}=0
\end{gathered}
$$

6) Area generation limits

$$
\begin{aligned}
\sum_{i} P g_{i, j}^{k} \leq \sum_{i} \overline{P g_{i}^{k}}-R_{j}^{k} ; k=1 \ldots N_{A} ; j=1 \ldots t \\
\sum_{i} P g_{i, j}^{k} \geq \sum_{i} \underline{P g}_{i}^{k} ; k=1 N_{A} ; j=1 \ldots t
\end{aligned}
$$

Each $F^{k}\left(P g_{i, j}^{k}\right)$ for $k=1 \ldots, N_{A}$ is represented in the form of schedule tables, which is the solution of the mixed variables optimisation problem

$$
\min _{I, P} \sum_{i}\left[I_{i, j}^{k} F_{i}^{k}\left(P g_{i, j}^{k}\right)+I_{i, j}\left(1-I_{i, j-1}\right) S_{i}\left(X_{i, j}^{\text {off }}\right)\right.
$$

Subject to constraints of Equation (7), (9-10) and initial on/off condition of each unit.

The multi-area unit commitment problem is solved by Dynamic Programming Sequential Combination (DP-SC) method to form the optimal generation scheduling approach. Among the available generating units in the interconnected multi-area system and the proposed method sequentially identifies, via a procedure that resembles bidding, the most advantageous units to commit until the multi-area system obligations are fulfilled and this method has been explained [13].

\subsection{Multi-Area Economic Dispatch}

The objective of Multi-area Economic Dispatch (MAED) is to determine the allocation of generation of each unit in the system and power exchange between areas so as to minimize the total production cost. The lamda-iteration method is implemented in the MAED to include area import and export constraints and tie-line constraints [15]

The objective is to select $\lambda_{s y s}$ every hour to minimize the operation cost.

$$
P g_{j}^{k}=D_{j}^{k}+E_{j}^{k}-L_{j}^{k}
$$

where $P g_{j}^{k}=\sum_{i=1}^{N_{k}} P g_{i, j}^{k}$

Since the local demand $D_{j}^{k}$ is determined in accordance with the economic dispatch within the pool, changes of $P_{g j}^{k}$ will cause the spinning reserve constraint of Equation (7) to change accordingly and redefine Equation(18).

In this study, the iterative equal incremental cost method ( $\lambda$ method) was used to solve Equation (11) and serve as a coordinator between unit commitments in various areas. With the $\lambda$ iteration, the system would operate at an optimal point if $\lambda$ for each unit is equal to a system incremental cost $\lambda_{\text {sys }}$. Units may operate in one of the following modes when commitment schedule and unit generation limits are encountered:

1) Coordinate mode: The output of unit $i$ is determined by the system incremental cost

$$
\lambda_{\min , i} \leq \lambda_{\text {sys }} \leq \lambda_{\max , i}
$$

2) Minimum mode: Unit i generation is at its minimum level.

$$
\lambda_{\min , i}>\lambda_{\text {sys }}
$$

3) Maximum mode: Unit i generation is at its maximum level.

$$
\lambda_{\max , i}<\lambda_{\text {sys }}
$$

4) Shut down mode: Unit $\mathrm{i}$ is not in operation, $P g_{i}=0$.

Besides limitations on individual unit generations, in a multi-area system, the tie-line constraints in Equation (9), (10) and (14) are to be preserved. The operation of each area could be generalized into one of three modes as follows:

Area coordinate mode

$$
\begin{gathered}
\lambda^{k}=\lambda_{\text {sys }} \\
D_{j}^{k}-L_{\max }^{k} \leq \sum_{i} P_{i, j}^{k} \leq D_{j}^{k}+E_{\max }^{k}
\end{gathered}
$$

or

$$
-L_{\max }^{k} \leq \sum_{i} P g_{i, j}^{k}-D_{j}^{k} \leq E_{\max }^{k}
$$

a. Limited export mode

When the generating cost in one area is lower than the cost in the remaining areas of the system, that area may generate its upper limit according to Equation (13) or (16), therefore, 


$$
\lambda^{k}<\lambda_{\text {sys }}
$$

$\lambda^{k}$ is the optimal equal incremental cost which satisfies the generation requirement in each area $\mathrm{k}$.

b. Limited import mode

An area may reach its lower generation limit according to Equation (14) or (17), because of the higher generation costs.

$$
\lambda_{\min }^{k}>\lambda_{\text {sys }}
$$

The proper generation schedule in multi-area will result by satisfying tie-line constraints and minimizing the system generation cost.

\subsection{Tie-Line Flow of Four Areas}

An economically efficient area may generate more power than the local demand, the excess power will be exported to the other areas through the tie-lines. As shown in Fig. 1 , assume area 1 has excess power, the line flows would have directions from area 1 to other areas, and the maximum power generation for area 1 would be the local demand in area 1 plus the sum of all the tie-line capacities connected to area 1 . If we fix the area 1 generation at its maximum level, then the maximum power generation in area 2 could be calculated in a similar way to area 1 .

Since tie-line imports power at its maximum capacity, this amount should be subtracted from the generation limit of area 2. According to the system power balance equation some areas must have a power generation deficiency, and require generation imports. The minimum generation level of these areas is the local demand, minus all the connected tie-line capacities. If any of these tie lines is connected to an area with higher deficiencies, then the flow directions should be reversed. The tie-line flow details of four area and directional matrix were presented in [9].

Directional matrix: It indicates power flow direction from one area to another area.

$D_{l, k}=[1$ when line flows from $l$ to $\mathrm{k} l>\mathrm{k}[-1$ when line flows from $\mathrm{k}$ to $l$

$$
D_{l, l}=0, D_{l . k}=-D_{k, l} \text { initial } D_{l . k} \text { are zero }
$$

\section{Evolutionary Programming Method}

\subsection{Introduction}

EP is a mutation-based evolutionary algorithm applied to discrete search spaces. D. Fogel (Fogel, 1988)] extended the initial work of his father L. Fogel (Fogel, 1962) [15-18] for applications involving real-parameter optimization problems. Real-parameter EP is similar in prin

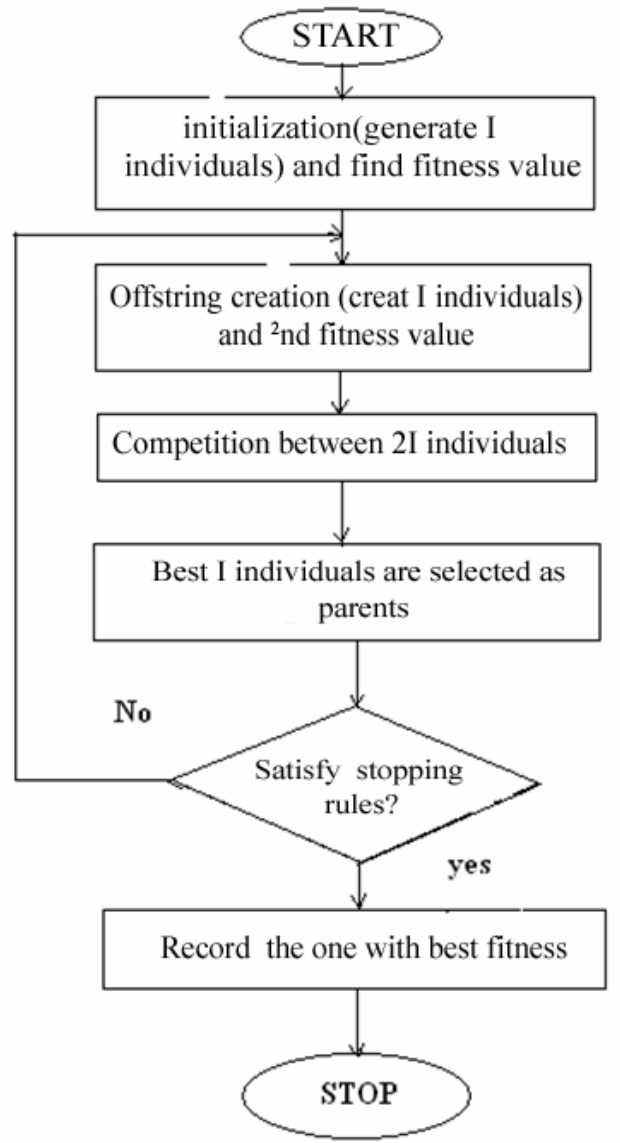

Figure 1. Flow chart for evolutionary algorithm.

ciple to evolution strategy (ES), in that normally distributed mutations are performed in both algorithms. Both algorithms encode mutation strength (or variance of the normal distribution) for each decision variable and a self-adapting rule is used to update the mutation strengths. Several variants of EP have been suggested (Fogel, 1992).

\subsection{Evolutionary Programming Algorithm}

The original Evolutionary Programming involved evolving populations of extending algorithms to develop artificial intelligence [17]. In this technique a strong behavioral link is sought between each parent and its offspring, at the level of the species.Fig. 1 shows e general scheme of the EP algorithm.

\subsection{Implementation of Evolutionary Algorithm for Multi-Area Unit Commitment Problem}

Step (1): Read in unit data, tie-line data, demand profile. Step (2): Perform the dynamic programming to get the initial commitment schedule for each area. 
Step (3): Initialization of parent population. The initial parent population of size $\mathrm{Np}$ is randomly generated for committed unit in each area:

1) To generate the initial parent population

$$
I_{p}=\left[\left(p_{g 1}^{k p} \ldots \ldots . . . p_{g N}^{k p}\right)\right] ; k=1,2,3,4 \& p=1,2 \ldots N_{p} ;
$$

2) To calculate the fuel cost for each population using Equation (1)

$$
F C_{p}^{K}=\left[\left(a\left(P g_{1}^{k p}\right)^{2}+b\left(P g_{1}^{k p}\right)+c\right) ; k=1,2,3,4 \& p=1,2 \ldots N_{p}\right.
$$

3) To calculate the start up cost for each population using Equation (4)

4) To calculate the production cost Production

$$
\cos \mathrm{t}=F C_{p}^{k}+S C_{p}^{k}
$$

5) To calculate the fitness function for each parent of population

$$
F_{P}=F C_{P}^{K}+S C_{P}^{K}+K\left(\sum_{i=1}^{N k} P G_{i}^{k p}-D_{j}^{k}\right)
$$

The values of the penalty factor is chosen such that if there are any constraints violations then the fitness function value corresponding to that parent will be ineffective.

Step (4): Mutation

1) To generate an offspring population Io of size from $\mathrm{Np}$ from each parent Ip

$$
I_{O}=\left[\left(P g_{1}^{k o} \ldots \ldots . . P g_{N}^{k o}\right) ; k=1,2,3,4 ; 0=1 \ldots . . N_{p}\right.
$$

generated as

$$
P g_{i}^{K O}=P g_{i}^{K O}+N\left(0, \sigma^{2} P g_{i}^{K}\right) ; i=1,2 \ldots \ldots . N
$$

Similarly all $P g_{i}$ is generated for all areas subjected to

$$
\begin{gathered}
\mathrm{Pg}_{\mathrm{i}}^{\mathrm{ko}}=\mathrm{Pg}_{i, \text { min }} ; \text { if } \mathrm{Pg}_{\mathrm{i}}^{\mathrm{ko}}<\mathrm{Pg}_{i, \text { min }} \\
\mathrm{Pg}_{\mathrm{i}}^{\mathrm{ko}}=\mathrm{Pg}_{i, \text { max }} ; \text { if } \mathrm{Pg}_{\mathrm{i}}^{\mathrm{KO}}>\mathrm{Pg}_{i, \text { max }}
\end{gathered}
$$

$N\left(0, \sigma^{2}\right)$ represents a normal random variable with zero mean and standard deviation

$$
\sigma_{P g_{i}}=\beta *\left(F_{p i} / F_{\max }\right) *\left(\sigma_{i j, \max }-\sigma_{i j, \min }\right)
$$

where $\beta$ is scaling factor, $F_{p i}$ is the value of fitness function corresponding to $I_{i}$ and $F_{\max }$ is the maximum fitness function value among parent population

2) To compute the fitness value corresponding to each offspring using Equation (31)

Step (5): (competition and selection). The $2 I$ individuals compete with each other for selection using Equation (6). A weight value $W_{i}$ is assigned to each individual as follows:

$$
\begin{gathered}
W_{i}=\sum_{t=1}^{I} W_{t} \\
W_{t}=\left\{1, \text { if } \quad u<\left(f_{t} / f_{t}+f_{i}\right)\right. \\
W_{t}=\{0, \text { otherwise }
\end{gathered}
$$

where $f_{t}$ is the fitness of the $i^{\text {th }}$ competitor randomly selected from $2 I$ individuals and $u$ is a uniform random number ranging over $[0,1]$. While computing the weight for each individual, it is ensured that each individual is selected only once from the combined population. Even though relative fitness values are used during the process of mutation, competition and selection, it leads to slow convergence. This is because the ratio $f_{t} /\left(f_{t}+f_{i}\right)$ is always around 0.5 without uniform distribution between 0 and 1.Hence, the following strategy is followed in this paper to assign weights:

$$
\begin{gathered}
W_{t}=\left\{1, \text { if } f_{t} /\left(f_{t}+f_{i}\right)>0.5\right. \\
W_{t}=\{0, \text { otherwise }
\end{gathered}
$$

This weight assignment is found to yield proper selection and good convergence. When all the $2 I$ individuals obtain their weights, they are ranked in descending order and the first $I$ individuals are selected as parents along with their fitness values for next generation.

Steps (4) and Steps (5) are repeated until there is no appreciable improvement in the minimum fitness value.

Step (6): Optimum generation schedule is obtained for four areas using minimum fitness value. Check area generation with local demand

Step (7): Areas with lower fuel cost may export the excessive generation to other areas with higher fuel cost (deficiency areas) with tie line limit.

\section{Particle Swarm Optimization}

Particle swarm optimization (PSO) is inspired from the collective behavior exhibited in swarms of social insects [19]. It has turned out to be an effective optimizer in dealing with a broad variety of engineering design problems. In PSO, a swarm is made up of many particles, and each particle represents a potential solution (i.e., individual). A particle has its own position and flight velocity, which are adjusted during the optimization process based on the following rules:

$V_{i}^{P+1}=\omega * V_{i}^{P}+C_{1} * \operatorname{rand}() *\left(P_{b i}^{K P}-P_{i}^{K P}\right)+C_{2} * \operatorname{rand}() *\left(P_{g i}^{K P}-P_{i}^{K P}\right)$

$$
P_{i}^{K P}=P_{i}^{K P}+V_{i}^{P+1}
$$

where $V_{t+1}$ is the updated particle velocity in the next iteration, $V_{t}$ is the particle velocity in the current iteration, $\omega$ is the inertia dampener which indicates the im- 
pact of the particle's own experience on its next movement, $C_{1}$ * rand represents a uniformly distributed number within the interval $[0, c 1]$, which reflects how the neighbours of the particle affects its flight, $P_{b i}^{K P}$ is the neighbourhood best position, $V_{i}^{P}$ is the current position of the particle and $C_{2}$ *rand represents a uniformly distributed number within the interval $[0, c 2]$, which indicates how the particle trusts the global best position, $P_{g i}^{K P}$ is the global best position, and $V_{i}^{P+1}$ is the updated position of the particle. Under the guidance of these two updating rules, the particles will be attracted to move towards the best position found thus far. That is, the optimal solutions can be sought out due to this driving force.

The major steps involved in Particle Swarm Optimization approach are discussed below:

1) Initialization

The initial particles are selected randomly and the velocities of each particle are also selected randomly. The size of the swarm will be ( $\mathrm{Np} \times \mathrm{n})$, where $\mathrm{Np}$ is the total number of particles in the swarm and ' $n$ ' is the number of stages.

\section{2) Updating the Velocity}

The velocity is updated by considering the current velocity of the particles, the best fitness function value among the particles in the swarm. The velocity of each particle is modified by using Equation (28)

The value of the weighting factor $\omega$ is modified by following Equation (40) to enable quick convergence.

$$
\omega=\omega_{\max }-\left(\omega_{\max }-\omega_{\min }\right) / \text { iter }_{\max } * \text { iter }
$$

The term $\omega<1$ is known as the "inertia weight" and it is a friction factor chosen between 0 and 1 in order to determine to what extent the particle remains along its original course unaffected by the pull of the other two terms. It is very important to prevent oscillations around the optimal value.

3) Updating the Position

The position of each particle is updated by adding the updated velocity with current position of the individual in the swarm

\subsection{Algorithm of Particle Swarm Optimization}

The step by step procedure to compute the global optimal solution is followed.

Step (1): Initialize a population of particles with random positions and velocities on $\mathrm{d}$ dimensions in the problem space.

Step (2): For each particle, evaluate the desired optimization fitness function in the variables.

Step (3): compare particles fitness evolution with particles Pbest. If current value is better then Pbest, then set Pbest value equal to the current value, and the Pbest location equal to the current location in the dimensional space.

Step (4): Compare fitness evaluation with the populations overall previous Pbest. If current value is better than gbest, then reset to the current particles array index and value.

Step (5): Change the velocity and position of the particle according to Equations (38) and (39) respectively.

Step (6): Loop to step 2 until a criterion is met, usually a sufficiently good fitness or a maximum number of iterations.

\subsection{Implementation of Particle Swarm Optimization Algorithm for Multi-Area Unit Commitment}

The various steps of the PSO algorithm are given below for solving multi area unit commitment problem:

Step (1): Read in unit data, tie-line data, load demand profile.

Step (2): Perform the dynamic programming to get the initial commitment schedule for each area.

Step (3): Initialization of particle . The initial particle of size $\mathrm{Np}$ is generated randomly for committed unit in each area :

1) Calculate the initial particle population

$$
I_{p}=\left[\left(P_{1}^{k p} \ldots . . P_{2}^{k p}\right) ; k=1,2,3,4: p=1 \ldots . . N_{p}\right.
$$

2) Calculate the fuel cost for each particle using Equation (1)

$$
F C_{p}^{k}=\left[\left(a\left(P_{1}^{k p}\right)^{2}+b\left(P_{1}^{k p}\right)+c\right) ; k=1,2,3,4 ; p=1,2 \ldots N_{p}\right.
$$

3) Calculate start up cost of each particle using Equation (4)

4) Calculate the production cost Production

$$
\operatorname{Cost}=\mathrm{FC}_{\mathrm{p}}^{\mathrm{k}}+S C_{p}^{k}
$$

5) Calculate the fitness function for each particle of population

$$
F_{p}=\mathrm{FC}_{\mathrm{p}}^{\mathrm{k}}+S C_{p}^{k}+k\left(\sum_{i=1}^{N_{k}} P_{i}^{k p}-D_{j}^{k}\right)
$$

6) To calculate the Pbest by using fitness function values, If current value is better then previous Pbest, then set Pbest value equal to the current value and compute gbest if current value is.

Step (4): Updating the Velocity

The velocity is updated by considering the current velocity of the particles, the best fitness function value among the particles in the swarm using following Equation (45).

$V_{i}^{P+1}=\omega * V_{i}^{P}+C_{1} * \operatorname{rand}() *\left(P_{b i}^{K P}-P_{i}^{K P}\right)+C_{2} * \operatorname{rand}() *\left(P_{g i}^{K P}-P_{i}^{K P}\right)$ 
where $\omega$ is weight factor, The weight $\omega$ is computed using Equation (40)

Step (5): Updating the particle position

The position of each particle is updated by adding the updated velocity with current position of the individual in the swarm.

$$
P_{i}^{K P}=P_{i}^{K P}+V_{i}^{P+1}
$$

The steps described in sub Sections 3 to 5 are repeated until a criterion is met, usually a sufficiently good fitness the maximum generation count is reached. Step (6): Optimum generation schedule is obtained for four area using gbest particle. Check area generation with local demand.

Step (7): Areas with lower fuel cost may export the excessive generation to areas with higher fuel cost (deficiency areas) with tie line limit

\section{Test System and Simulation Results}

The proposed MAUC algorithm has been implemented in $\mathrm{C}++$ environment and tested extensively. Test results of a multi-area system are presented in this section. All simulations are performed in a PC with Intel processor $(1.953 \mathrm{GHz})$ and $1012 \mathrm{MB}$ of RAM.

As shown in Figure 2, a sample multi-area system with four areas, IEEE reliability test system, 1996 data in [9], are used to test the speed of solving the multi-area UC and ED for a large-scale system with import/export capability and tie line capacity constraints. In the sample multi-area system, each area consists of 26 units. The total number of units tested is 104 , and their characteristics are presented in [9]. There are some identical thermal units also located in each area. The system contains five tie lines four area interconnections as shown in Figure 4 , and area one is the reference area. Figure 3 shows the modified same load demand profile forecast used in all four areas. The assumptions described in tie line capacity constraint are applied to the simulations.

The four areas have the same load demand profiles. As the load demand is same in these four areas, the economical area will generate more power than expensive areas. Figure 3 gives the changes in area 1 power generation, committed unit capacities, unit commitment pattern of hour $7 \mathrm{am}$ and spinning reserve requirement of area 1 is $400 \mathrm{MW}$, because the available unit capacities are not more than the power generation plus the spinning reserve. This phenomenon proves that the available capacity should comply with the area power generation instead of the local load demand.

The systems 1 oad demand is $6800 \mathrm{MW}$, so area 1 generation increases steadily while that of area 2,3 decreases. The incremental cost of area 2, 3 is higher than

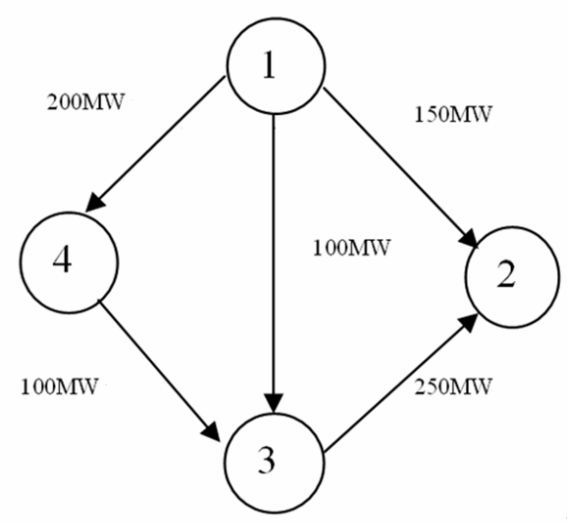

Figure 2. Topological connections of four areas.

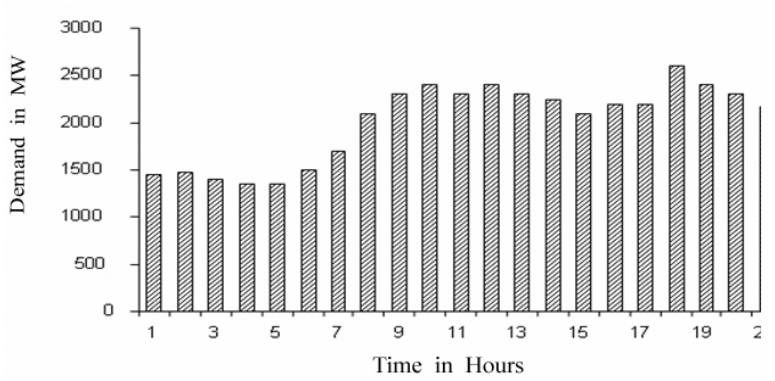

Figure 3. Load pattern for all four -area.

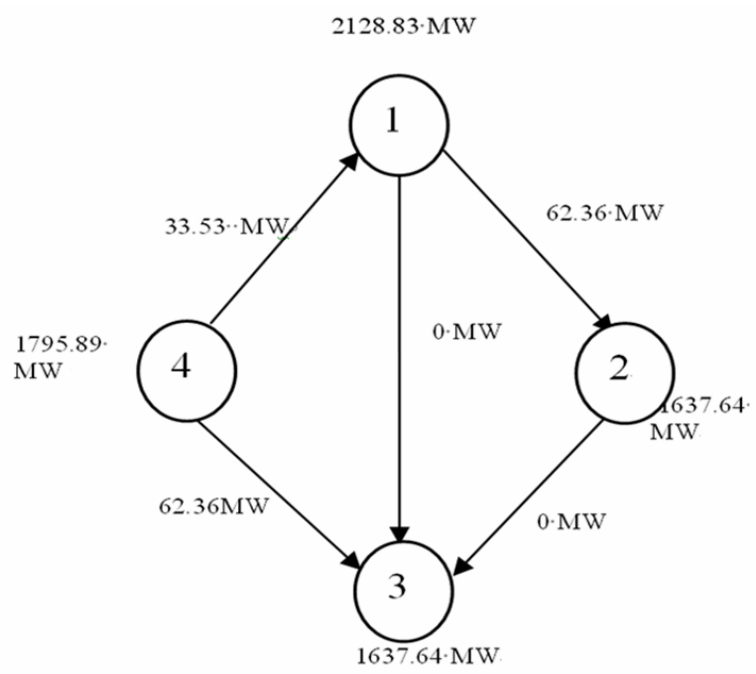

Figure 4.Tie-line flow pattern for $7 \mathrm{am}$.

that of the other two areas since the tie flows to area 2, 3 are at their maximum capacities. This manifests that the proposed method considers tie-line limits effectively.

Table I shows that parameter used in EP and PSO method. Table 2, 3, 4 and Table $\mathrm{V}$ shows comparison result of DP and EP, PSO. Figure 4 and 5 shows the convergence characteristics for multi-area obtained using proposed methodology.

Table 2 shows that the total production cost is obta- 
Table 1. Parameter used in EP \& PSO.

\begin{tabular}{|l|c|c|}
\hline \multicolumn{1}{|c|}{ Parameter } & EP & PSO \\
\hline Population size(p) & 10 & 10 \\
\hline Mutation scaling factor( $\beta$ ) & 0.03 & - \\
\hline Penalty factor(k1) & 10000 & \multicolumn{2}{|c|}{1000} \\
\hline Maximum Generation & 500 & 500 \\
\hline Learning factor(c1,c2) & - & 2 \\
\hline
\end{tabular}

ined by using conventional method. Table 3 and 4 shows that the total production cost is obtained for ten iterations by using EP and PSO method. Figure 4 gives the plot of EP average performance from 500 runs. Figure 5 gives the plot of number of iteration versus the time taken to complete those iterations and the maximum production cost obtained under each iteration using PSO method.

As we indicated in the paper, the PSO algorithm has also proved to be an efficient tool for solving the multi -area unit commitment with economic dispatch problem. There is no obvious limitation on the size of the problem that must be addressed, for its data structure is such that the search space is reduced to a minimum; no "relaxation of constraints" is required; instead, populations of feasible solutions are produced at each generation and throughout the evolution process. The main advantages of the proposed algorithm are speed.

The proposed PSO approach was compared to the related methods in the references indented to serve this purpose, such as the DP with a zoom feature, and the EP approaches. In addition, with the use of PSO method, the status is improved by avoiding the entrapment in local minima. By means of stochastically searching multiple points at one time and considering trial solutions of suc cessive generations, the PSO approach gives global minima instead of entrapping in local optimum solutions. The PSO method obviously displays a satisfactory performance with respect to the quality of its evolved solutions and to its computational requirements.

The final result of PSO would save $0.12 \% \$ 2865.4$ is compared with the solution obtained by the conventional method but it would require 33 seconds to complete the computation .So, the EP method is reduced the operating cost by $0.08 \%$ than the conventional method but it requires 36 seconds to complete this computation .From these results, the PSO method had less total cost and consumed also less CPU time compared to other method.

\section{Conclusions}

Application of PSO is a novel approach in solving the MAUC problem. Results demonstrate that PSO is a very competent method to solve the MAUC problem. PSO
Table 2. Operating cost of DP method.

\begin{tabular}{|c|c|c|c|c|}
\hline $\begin{array}{l}\text { Hours } \\
\text { (24) }\end{array}$ & $\begin{array}{l}\text { Area-1 } \\
\text { (26 Unit) }\end{array}$ & $\begin{array}{l}\text { Area-2 } \\
\text { (26 Unit) }\end{array}$ & $\begin{array}{l}\text { Area-3 } \\
\text { (26 Unit) }\end{array}$ & $\begin{array}{l}\text { Area-4 } \\
\text { (26 Unit) }\end{array}$ \\
\hline 1 & $\begin{array}{l}37115.330 \\
08\end{array}$ & $\begin{array}{l}24115.5214 \\
8\end{array}$ & $\begin{array}{l}28331.2265 \\
6\end{array}$ & $\begin{array}{l}22042.12 \\
500\end{array}$ \\
\hline 2 & $\begin{array}{l}24747.960 \\
94\end{array}$ & $\begin{array}{l}23137.6396 \\
5\end{array}$ & $\begin{array}{l}22994.8997 \\
4\end{array}$ & $\begin{array}{l}19289.81 \\
836\end{array}$ \\
\hline 3 & $\begin{array}{l}27995.107 \\
42\end{array}$ & $\begin{array}{l}23137.6396 \\
5\end{array}$ & $\begin{array}{l}23701.2568 \\
4\end{array}$ & $\begin{array}{l}19175.97 \\
998\end{array}$ \\
\hline 4 & $\begin{array}{l}29576.867 \\
19\end{array}$ & $\begin{array}{l}18274.3261 \\
7\end{array}$ & $\begin{array}{l}26151.8378 \\
9\end{array}$ & $\begin{array}{l}18397.77 \\
637\end{array}$ \\
\hline 5 & $\begin{array}{l}29347.660 \\
16\end{array}$ & $\begin{array}{l}18329.3261 \\
7\end{array}$ & $\begin{array}{l}25595.4296 \\
9\end{array}$ & $\begin{array}{l}18698.77 \\
344\end{array}$ \\
\hline 6 & $\begin{array}{l}36118.037 \\
11\end{array}$ & $\begin{array}{l}18329.3261 \\
7\end{array}$ & $\begin{array}{l}23799.5097 \\
7\end{array}$ & $\begin{array}{l}19705.58 \\
106\end{array}$ \\
\hline 7 & $\begin{array}{l}40483.162 \\
11\end{array}$ & $\begin{array}{l}28104.1445 \\
3\end{array}$ & $\begin{array}{l}21999.5986 \\
3\end{array}$ & $\begin{array}{l}24891.27 \\
832\end{array}$ \\
\hline 8 & $\begin{array}{l}39248.855 \\
47\end{array}$ & $\begin{array}{l}32917.4687 \\
5\end{array}$ & $\begin{array}{l}19852.8554 \\
7\end{array}$ & $\begin{array}{l}21117.69 \\
727\end{array}$ \\
\hline 9 & $\begin{array}{l}38728.734 \\
38\end{array}$ & $\begin{array}{l}34865.2382 \\
8\end{array}$ & $\begin{array}{l}18245.3730 \\
5\end{array}$ & $\begin{array}{l}21253.34 \\
180\end{array}$ \\
\hline 10 & $\begin{array}{l}37215.339 \\
84\end{array}$ & $\begin{array}{l}32205.3750 \\
0\end{array}$ & $\begin{array}{l}22093.5957 \\
0\end{array}$ & $\begin{array}{l}24255.43 \\
945\end{array}$ \\
\hline 11 & $\begin{array}{l}37193.468 \\
75\end{array}$ & $\begin{array}{l}32205.3750 \\
0\end{array}$ & $\begin{array}{l}20244.0820 \\
3\end{array}$ & $\begin{array}{l}23298.57 \\
031\end{array}$ \\
\hline 12 & $\begin{array}{l}38310.472 \\
66\end{array}$ & $\begin{array}{l}32205.3750 \\
0\end{array}$ & $\begin{array}{l}20992.8925 \\
8\end{array}$ & $\begin{array}{l}21298.69 \\
336\end{array}$ \\
\hline 13 & $\begin{array}{l}33225.353 \\
52\end{array}$ & $\begin{array}{l}34149.0293 \\
0\end{array}$ & $\begin{array}{l}18152.8222 \\
7\end{array}$ & $\begin{array}{l}26442.17 \\
773\end{array}$ \\
\hline 14 & $\begin{array}{l}31623.279 \\
30\end{array}$ & $\begin{array}{l}37085.8281 \\
3\end{array}$ & $\begin{array}{l}17146.9394 \\
5\end{array}$ & $\begin{array}{l}25955.68 \\
945\end{array}$ \\
\hline 15 & $\begin{array}{l}30595.626 \\
95\end{array}$ & $\begin{array}{l}33172.8613 \\
3\end{array}$ & $\begin{array}{l}17991.4726 \\
6\end{array}$ & $\begin{array}{l}23682.43 \\
359\end{array}$ \\
\hline 16 & $\begin{array}{l}36312.250 \\
00\end{array}$ & $\begin{array}{l}32989.6523 \\
4\end{array}$ & $\begin{array}{l}22492.5781 \\
3\end{array}$ & $\begin{array}{l}25305.94 \\
336\end{array}$ \\
\hline 17 & $\begin{array}{l}36925.175 \\
78\end{array}$ & $\begin{array}{l}32989.6523 \\
4\end{array}$ & $\begin{array}{l}23769.5800 \\
8\end{array}$ & $\begin{array}{l}25383.72 \\
656\end{array}$ \\
\hline 18 & $\begin{array}{l}35682.320 \\
31\end{array}$ & $\begin{array}{l}39459.6250 \\
0\end{array}$ & $\begin{array}{l}27589.7597 \\
7\end{array}$ & $\begin{array}{l}19501.75 \\
391\end{array}$ \\
\hline 19 & $\begin{array}{l}35682.320 \\
31\end{array}$ & $\begin{array}{l}39903.0585 \\
9\end{array}$ & $\begin{array}{l}23860.8418 \\
0\end{array}$ & $\begin{array}{l}22304.66 \\
016\end{array}$ \\
\hline 20 & $\begin{array}{l}35682.320 \\
31\end{array}$ & $\begin{array}{l}32114.9414 \\
1\end{array}$ & $\begin{array}{l}21973.3906 \\
3\end{array}$ & $\begin{array}{l}15999.40 \\
332\end{array}$ \\
\hline 21 & $\begin{array}{l}38042.478 \\
52\end{array}$ & $\begin{array}{l}29387.7168 \\
0\end{array}$ & $\begin{array}{l}19907.5390 \\
6\end{array}$ & $\begin{array}{l}20248.24 \\
805\end{array}$ \\
\hline 22 & $\begin{array}{l}30190.896 \\
48\end{array}$ & $\begin{array}{l}15095.1718 \\
8\end{array}$ & $\begin{array}{l}21115.4316 \\
4\end{array}$ & $\begin{array}{l}21807.76 \\
953\end{array}$ \\
\hline 23 & $\begin{array}{l}30923.708 \\
98\end{array}$ & $\begin{array}{l}18398.0820 \\
3\end{array}$ & $\begin{array}{l}19966.2128 \\
9\end{array}$ & $\begin{array}{l}22309.07 \\
813\end{array}$ \\
\hline 24 & $\begin{array}{l}30202.210 \\
94\end{array}$ & $\begin{array}{l}15198.7812 \\
5\end{array}$ & $\begin{array}{l}19815.6132 \\
8\end{array}$ & $\begin{array}{l}18294.49 \\
805\end{array}$ \\
\hline $\begin{array}{l}\text { Total } \\
\text { cost }\end{array}$ & $\begin{array}{l}821168.93 \\
75\end{array}$ & $\begin{array}{l}677771.156 \\
3\end{array}$ & $\begin{array}{l}527784.731 \\
2\end{array}$ & $\begin{array}{l}520660.4 \\
566\end{array}$ \\
\hline
\end{tabular}

generates better solutions than the other methods, mainly because of its intrinsic nature of updates of positions and velocities. The reason is due to the hourly basis solution. This is somehow similar to the "divide and conquer" strategy of solving a problem. Owning to this 
Table 3. Opearting cost of EP method.

\begin{tabular}{|c|c|c|c|c|}
\hline $\begin{array}{l}\text { Hour } \\
\text {-s } \\
(24)\end{array}$ & $\begin{array}{l}\text { Area-1 } \\
\text { (26 Unit) }\end{array}$ & $\begin{array}{l}\text { Area-2 } \\
\text { (26 Unit) }\end{array}$ & $\begin{array}{l}\text { Area-3 } \\
\text { (26 Unit) }\end{array}$ & $\begin{array}{l}\text { Area-4 } \\
\text { (26 Unit) }\end{array}$ \\
\hline 1 & $\begin{array}{l}37112.330 \\
08\end{array}$ & $\begin{array}{l}24093.521 \\
48\end{array}$ & $\begin{array}{l}28311.2265 \\
6\end{array}$ & 22002.12500 \\
\hline 2 & $\begin{array}{l}24741.960 \\
94\end{array}$ & $\begin{array}{l}23127.639 \\
65\end{array}$ & $\begin{array}{l}22964.8997 \\
4\end{array}$ & 19259.81836 \\
\hline 3 & $\begin{array}{l}27988.107 \\
42\end{array}$ & $\begin{array}{l}23127.639 \\
65\end{array}$ & $\begin{array}{l}23681.2568 \\
4\end{array}$ & 19151.97998 \\
\hline 4 & $\begin{array}{l}29566.867 \\
19\end{array}$ & $\begin{array}{l}18254.326 \\
17\end{array}$ & $\begin{array}{l}26121.8378 \\
9\end{array}$ & 18367.77637 \\
\hline 5 & $\begin{array}{l}29337.660 \\
16\end{array}$ & $\begin{array}{l}18309.326 \\
17\end{array}$ & $\begin{array}{l}25572.4296 \\
9\end{array}$ & 18678.77344 \\
\hline 6 & $\begin{array}{l}36108.037 \\
11\end{array}$ & $\begin{array}{l}18309.326 \\
17\end{array}$ & $\begin{array}{l}23789.5097 \\
7\end{array}$ & 19683.58106 \\
\hline 7 & $\begin{array}{l}40473.162 \\
11\end{array}$ & $\begin{array}{l}28084.144 \\
53\end{array}$ & $\begin{array}{l}21975.5986 \\
3\end{array}$ & 24861.27832 \\
\hline 8 & $\begin{array}{l}39238.855 \\
47\end{array}$ & $\begin{array}{l}32897.468 \\
75\end{array}$ & $\begin{array}{l}19822.8554 \\
7\end{array}$ & 21087.69727 \\
\hline 9 & $\begin{array}{l}38718.734 \\
38\end{array}$ & $\begin{array}{l}34841.238 \\
28\end{array}$ & $\begin{array}{l}18215.3730 \\
5\end{array}$ & 21223.34180 \\
\hline 10 & $\begin{array}{l}37202.339 \\
84\end{array}$ & $\begin{array}{l}32185.375 \\
00\end{array}$ & $\begin{array}{l}22063.5957 \\
0\end{array}$ & 24205.43945 \\
\hline 11 & $\begin{array}{l}37183.468 \\
75\end{array}$ & $\begin{array}{l}32185.375 \\
00\end{array}$ & $\begin{array}{l}20224.0820 \\
3\end{array}$ & 23278.57031 \\
\hline 12 & $\begin{array}{l}38296.472 \\
66\end{array}$ & $\begin{array}{l}32185.375 \\
00\end{array}$ & $\begin{array}{l}20972.8925 \\
8\end{array}$ & 21268.69336 \\
\hline 13 & $\begin{array}{l}33212.353 \\
52\end{array}$ & $\begin{array}{l}34129.029 \\
30\end{array}$ & $\begin{array}{l}18132.8222 \\
7\end{array}$ & 26412.17773 \\
\hline 14 & $\begin{array}{l}31607.279 \\
30\end{array}$ & $\begin{array}{l}37063.828 \\
13\end{array}$ & $\begin{array}{l}17126.9394 \\
5\end{array}$ & 25920.68945 \\
\hline 15 & $\begin{array}{l}30578.626 \\
95\end{array}$ & $\begin{array}{l}33152.861 \\
33\end{array}$ & $\begin{array}{l}17981.4726 \\
6\end{array}$ & 23642.43359 \\
\hline 16 & $\begin{array}{l}36281.250 \\
00\end{array}$ & $\begin{array}{l}32969.652 \\
34\end{array}$ & $\begin{array}{l}22462.5781 \\
3\end{array}$ & 25286.94336 \\
\hline 17 & $\begin{array}{l}36919.175 \\
78\end{array}$ & $\begin{array}{l}32969.652 \\
34\end{array}$ & $\begin{array}{l}23749.5800 \\
8\end{array}$ & 25353.72656 \\
\hline 18 & $\begin{array}{l}35662.320 \\
31\end{array}$ & $\begin{array}{l}39439.625 \\
00\end{array}$ & $\begin{array}{l}27569.7597 \\
7\end{array}$ & 19471.75391 \\
\hline 19 & $\begin{array}{l}35662.320 \\
31\end{array}$ & $\begin{array}{l}39893.058 \\
59\end{array}$ & $\begin{array}{l}23839.8418 \\
0\end{array}$ & 22274.66016 \\
\hline 20 & $\begin{array}{l}35662.320 \\
31\end{array}$ & $\begin{array}{l}32094.941 \\
41\end{array}$ & $\begin{array}{l}21943.3906 \\
3\end{array}$ & 15969.40332 \\
\hline 21 & $\begin{array}{l}38032.478 \\
52\end{array}$ & $\begin{array}{l}29365.716 \\
8\end{array}$ & $\begin{array}{l}19887.5390 \\
6\end{array}$ & 20218.24805 \\
\hline 22 & $\begin{array}{l}30177.896 \\
48\end{array}$ & $\begin{array}{l}15065.171 \\
88\end{array}$ & $\begin{array}{l}21073.4316 \\
4\end{array}$ & 21797.76953 \\
\hline 23 & $\begin{array}{l}30913.708 \\
98\end{array}$ & $\begin{array}{l}18387.082 \\
03\end{array}$ & $\begin{array}{l}19946.2128 \\
9\end{array}$ & 22279.07813 \\
\hline 24 & $\begin{array}{l}30182.210 \\
94\end{array}$ & $\begin{array}{l}15168.781 \\
25\end{array}$ & $\begin{array}{l}19796.6132 \\
8\end{array}$ & 18254.49805 \\
\hline $\begin{array}{l}\text { Total } \\
\text { cost }\end{array}$ & $\begin{array}{l}820859.93 \\
75\end{array}$ & $\begin{array}{l}677300.15 \\
62\end{array}$ & $\begin{array}{l}527225.739 \\
6\end{array}$ & 519950.4565 \\
\hline
\end{tabular}

hourly solution, the complexity of the search is greatly reduced. The total objective function is the sum of objectives and constraints, which are fuel cost, start-up cost,
Table 4. Operating cost of PSO method.

\begin{tabular}{|c|c|c|c|c|}
\hline $\begin{array}{l}\text { Hours } \\
(24)\end{array}$ & $\begin{array}{l}\text { Area-1 } \\
\text { (26 Unit) }\end{array}$ & $\begin{array}{l}\text { Area-2 } \\
\text { (26 Unit) }\end{array}$ & $\begin{array}{l}\text { Area-3 } \\
\text { (26 Unit) }\end{array}$ & $\begin{array}{l}\text { Area-4 } \\
\text { (26 Unit) }\end{array}$ \\
\hline 1 & 37096.33008 & 24048.52148 & $\begin{array}{l}28309.226 \\
56\end{array}$ & $\begin{array}{l}21998.125 \\
00\end{array}$ \\
\hline 2 & 24514.96094 & 23004.63965 & $\begin{array}{l}22910.899 \\
74\end{array}$ & $\begin{array}{l}19251.818 \\
36\end{array}$ \\
\hline 3 & 27980.10742 & 23004.63965 & $\begin{array}{l}23674.256 \\
84\end{array}$ & $\begin{array}{l}19145.979 \\
98\end{array}$ \\
\hline 4 & 29568.86719 & 18286.32617 & $\begin{array}{l}26111.837 \\
89\end{array}$ & $\begin{array}{l}18374.776 \\
37\end{array}$ \\
\hline 5 & 29387.66016 & 18286.32617 & $\begin{array}{l}25578.429 \\
69\end{array}$ & $\begin{array}{l}18671.773 \\
44\end{array}$ \\
\hline 6 & 35838.03711 & 18286.32617 & $\begin{array}{l}23769.509 \\
77\end{array}$ & $\begin{array}{l}19673.581 \\
06\end{array}$ \\
\hline 7 & 40497.16211 & 28043.14453 & $\begin{array}{l}21945.598 \\
63 \\
\end{array}$ & $\begin{array}{l}24858.278 \\
32 \\
\end{array}$ \\
\hline 8 & 39228.85547 & 32977.46875 & $\begin{array}{l}19815.855 \\
47\end{array}$ & $\begin{array}{l}21081.697 \\
27\end{array}$ \\
\hline 9 & 38648.73438 & 34802.23828 & $\begin{array}{l}18245.373 \\
05\end{array}$ & $\begin{array}{l}21201.341 \\
80\end{array}$ \\
\hline 10 & 37229.33984 & 32191.37500 & $\begin{array}{l}22063.595 \\
70\end{array}$ & $\begin{array}{l}24199.439 \\
45\end{array}$ \\
\hline 11 & 37184.46875 & 32191.37500 & $\begin{array}{l}20212.082 \\
03\end{array}$ & $\begin{array}{l}23272.570 \\
31\end{array}$ \\
\hline 12 & 38294.47266 & 32191.37500 & $\begin{array}{l}20979.892 \\
58\end{array}$ & $\begin{array}{l}21262.693 \\
36\end{array}$ \\
\hline 13 & 33200.35352 & 34120.0293 & $\begin{array}{l}18127.822 \\
27\end{array}$ & $\begin{array}{l}26401.177 \\
73\end{array}$ \\
\hline 14 & 31630.27930 & 37051.82813 & $\begin{array}{l}17124.939 \\
45\end{array}$ & $\begin{array}{l}25928.689 \\
45\end{array}$ \\
\hline 15 & 30578.62695 & 33162.86133 & $\begin{array}{l}17978.472 \\
66\end{array}$ & $\begin{array}{l}23631.433 \\
59\end{array}$ \\
\hline 16 & 36281.25000 & 32960.65234 & $\begin{array}{l}22459.578 \\
13\end{array}$ & $\begin{array}{l}25277.943 \\
36\end{array}$ \\
\hline 17 & 36949.17578 & 32960.65234 & $\begin{array}{l}23748.580 \\
08\end{array}$ & $\begin{array}{l}25365.726 \\
56\end{array}$ \\
\hline 18 & 35766.32031 & 39439.62500 & $\begin{array}{l}27569.759 \\
77\end{array}$ & $\begin{array}{l}19465.753 \\
91\end{array}$ \\
\hline 19 & 35766.32031 & 39811.05859 & $\begin{array}{l}23839.841 \\
8\end{array}$ & $\begin{array}{l}22243.660 \\
16\end{array}$ \\
\hline 20 & 35766.32031 & 32081.94141 & $\begin{array}{l}21943.390 \\
63\end{array}$ & $\begin{array}{l}15968.403 \\
32\end{array}$ \\
\hline 21 & 38122.47852 & 29353.71680 & $\begin{array}{l}19897.539 \\
06\end{array}$ & $\begin{array}{l}20208.248 \\
05\end{array}$ \\
\hline 22 & 30177.89648 & 15065.17188 & $\begin{array}{l}21073.431 \\
64\end{array}$ & $\begin{array}{l}21791.769 \\
53\end{array}$ \\
\hline 23 & 31583.70898 & 18379.08203 & $\begin{array}{l}19966.212 \\
89\end{array}$ & $\begin{array}{l}22270.078 \\
13\end{array}$ \\
\hline 24 & 29449.21094 & 15159.78125 & $\begin{array}{l}19816.613 \\
28\end{array}$ & $\begin{array}{l}18211.498 \\
05\end{array}$ \\
\hline $\begin{array}{l}\text { Total } \\
\text { cost }\end{array}$ & 820740.9375 & 676860.1562 & $\begin{array}{l}527162.73 \\
96\end{array}$ & $\begin{array}{l}519756.45 \\
65\end{array}$ \\
\hline
\end{tabular}

spinning reserve, power demand, tie-line limit, and import and export constraints. For a better solution, generated powers by $\mathrm{N}$ unit of generators and $\mathrm{K}$ areas, tie -line limits are constantly checked so that feasible particles can meet the power demand.This reduces the pressure of 


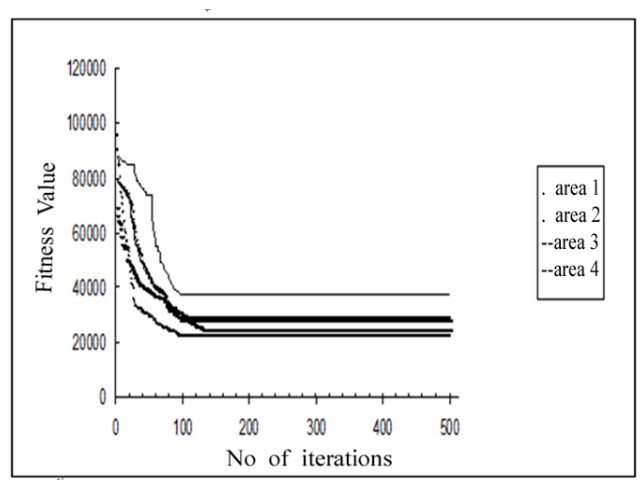

Figure 4. Convergence characteristics of EP method.

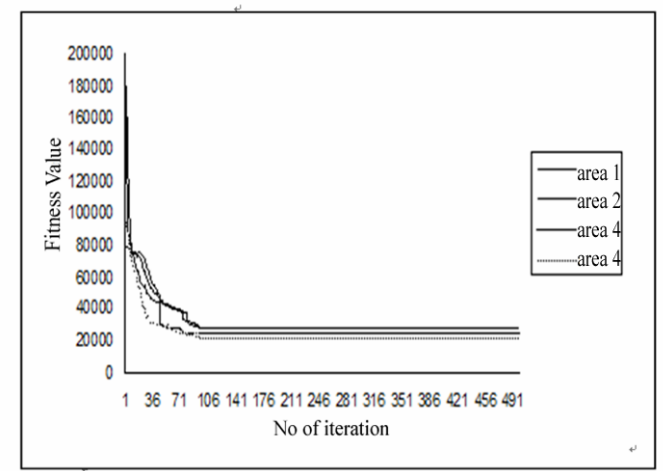

Figure 5. Convergence characteristics of PSO method.

Table 5. Comparison of DP, EP, PSO method.

\begin{tabular}{|l|l|l|l|l|l|l|}
\hline $\begin{array}{l}\text { Met } \\
\text { hod }\end{array}$ & $\begin{array}{l}\text { Area-1 } \\
(26)\end{array}$ & $\begin{array}{l}\text { Area-2 } \\
(26)\end{array}$ & $\begin{array}{l}\text { Area-3 } \\
(26)\end{array}$ & $\begin{array}{l}\text { Area-4 } \\
(26)\end{array}$ & $\begin{array}{l}\text { Total Cost } \\
(\$)\end{array}$ & $\begin{array}{l}\text { Time } \\
(\mathrm{S})\end{array}$ \\
\hline DP & 821168.9 & 677771.1 & 527784.7 & 520660.45 & 2547385.2 & 36.7 \\
\hline EP & 820859.7 & 677300.1 & 527225.9 & 519950.19 & 2545336.2 & 35.1 \\
\hline PSO & 820740.9 & 676860.1 & 527162.7 & 519756.45 & 2544519.3 & 34.2 \\
\hline
\end{tabular}

the constraint violation of the total objective function. Finally, the result obtained from the simulation is most encouraging in comparison to the best-known solution so far. In the future work, the power flow in each area can be considered to further increase the system security. Other issues such as transmission losses, transmission costs, call and put options policies between and bilateral contract areas can also be considered to reflect more realistic situations in MAUC problems.

\section{References}

[1] S. Salam, "Unit commitment solution methods," Proceedings of World Academy of Science, Engineering and Technology, Vol. 26, December 2007.

[2] B. Lu and M. shahidehpour, "Short term scheduling of combined cycle units," IEEE Transaction on Power System, Vol. 19, pp. 1616-1625, August 2004.
[3] F. Gao, "Economic dispatch algorithms for thermal unit system involving combined cycle units," IEEE and Gerald Bushel IEEE Lowa State University Ames, IA, USA, IEEE Transaction on Power Systems, pp. 1066-1072, November 2003.

[4] E. Fan, X. H. Guan, and Q. Z. Zhai, "A new method for unit commitment with ramping con straints," IEEE Transaction on Power Systems, March 2001.

[5] H. T. Yang and C. L. Huang, "Evolutionary programming based economic dispatch for units with non-smooth fuel cost functions," IEEE Transactions on power system, Vol. 11, No. 2, pp. 112-118, 1996.

[6] Z. Ouyang and S. M. Shahidehpour, "Heuristic multi-area unit commitment with economic dispatch," IEEE Proceedings, Vol. 138, No. 3, pp. 242-252, 1991.

[7] C. L. Tseng, "Multi-area unit commitment for large scale power system," IEEE Proceedings - Generation and Distribution, Vol. 145, No. 41, pp. 415-421, 1999.

[8] C. Wang and M. Shahidehpour, "A decomposition approach to non-linear multi-area generation scheduling with tie-line constraints using expert systems," IEEE Transactions on Power System, Vol. 7, No. 4, pp. 1409 $-1418,1992$.

[9] C. K. Pang, G. B. Sheble, and F. Albuyeh, "Evaluation of dynamic programming based methods and multiple area representation for thermal unit commitments," IEEE Transactions on Power Apparatus System, Vol. 100, No. 3, pp. 1212-1218, 1981.

[10] F. N. Lee, J. Huang, and R. Adapa, "Multi-area unit commitment via sequential method and a DC power flow network model," IEEE Transactions on Power System, Vol. 9, No. 1, pp. 279- 284, 1994.

[11] C. Yingvivatanapong, W. J. Lee, and E. Liu, "Multi-area power generation dispatch in competitive markets," IEEE Transactions on Power Systems, pp. 196-203, 2008.

[12] U. B. Fogel, "On the philosophical differences between evolutionary algorithms and genetic algorithms," IEEE Proceedindings in Second Annual Conference on Evolutionary Programming, pp. 23-29, 1993.

[13] T. Biick and H. P. Schwefel, "An overview of evolutionary algorithm for parameter optimization," Evolutionary Computation, Vol. 1, No. 1, pp. 1-24. 1993.

[14] C. C. Asir Rajan and M. R. Mohan, "An evolutionary programming-based tabu search method for solving the unit commitment problem," IEEE Transactions on Power System, Vol. 19, No. 1, pp. 577-585, 2004.

[15] D. Srinivasan, F. Wen, and C. S. Chang, "A survey of applications evolutionary computing to power systems," IEEE Proceedings, USA, pp. 35-41, 1996.

[16] J. Kennedy, "The particle swarm: Social adaptation of knowledge," Proceedings in International Conference on Evolutionary Computation, Indianapolis, pp. 303-308, 1997. 


\section{Appendix A}

Nomenclature

$D_{j}^{k}$

$L_{j}^{k}$

$E_{j}^{k}$

$I_{i, j}^{k}$

Irlist

$i$

$j$

$\lambda_{i}$

$\lambda_{\text {sys }}$

$N_{A}$

$N_{k}$

$O_{\text {plist }}$

$P g_{j}^{k}$

$P g_{i}^{k}$
Total load demand in area $\mathrm{k}$ at jth hour

Total import power to area $\mathrm{k}$ at jth hour

Total export power to area $\mathrm{k}$ at jth hour

Commitment state ( 1 on, 0 for off)

List of committed units ascending priority order

Index for units

Index for time

Lagrangian multiplier for unit

Lagrangian multiplier for entire system

Total number of areas

Total number of units in area $\mathrm{K}$

List of uncommitted units in descending order

Power generation of area $\mathrm{k}$ at $\mathrm{jth}$ hour

Lower limit of power generation of unit $\mathrm{i}$ in area $\mathrm{k}$
$\overline{P g_{i}^{k}}$

$P g_{i, j}^{k}$

$R_{j}^{k}$

$S_{j}^{k}$

$S D_{j}^{k}$

$T_{i}^{\text {on }}$

$T_{i}^{o f f}$

$\tau_{i}$

$W_{j}$ $X_{i, j}^{\text {on/off }}$
Upper limit of power generation of unit $i$ in area $\mathrm{k}$

Power generation of unit $i$ in area $k$ at $j$ th hour

Spinning reserve of area $\mathrm{k}$ at $\mathrm{j}$ th hour

Total commitment capacity for area $\mathrm{k}$ at $\mathrm{j}$ th hour

Total system demand at $\mathrm{j}$ th hour $t$ Total time span in hours

Minimum up time of unit $i$

Minimum down time of unit $i$

Time constant in start up cost function for unit $\mathrm{i}$

Net power exchange with outside systems

Time duration for which unit $\mathrm{i}$ has been on/off at $j^{\text {th }}$ hour 